\title{
The Recovery of Energy from a Hybrid System to Improve the Performance of a Photovoltaic Cell
}

\author{
Abdelhak Lekbir'1, Chin Kim Gan², Mohd Ruddin Ab Ghani ${ }^{3}$, Tole Sutikno ${ }^{4}$ \\ 1,2,3 Faculty of Electrical Engineering, Universiti Teknikal Malaysia Melaka, Hang Tuah Jaya, Melaka, Malaysia \\ ${ }^{4}$ Department of Electrical Engineering, Faculty of Industrial Technology, Universitas Ahmad Dahlan, Yogyakarta, \\ Indonesia
}

\begin{tabular}{l} 
Article Info \\
\hline Article history: \\
Received Dec 7, 2017 \\
Revised Apr 4, 2018 \\
Accepted Apr 24, 2018 \\
\hline
\end{tabular}

Keyword:

Photovoltaic

Thermoelectric

Hybrid Energy

Temperature

\begin{abstract}
The main objective of this work is to study a photovoltaic/thermoelectric hybrid generator system, ranging from characterisation of thermoelectric (TE) and photovoltaic (PV) modules basic elements of thermal and PV energy conversion into electrical energy through necessary modelling steps. The bibliographic study allows TE and PV generation to be positioned in the current context, by presenting their history and evolution. In some sectors, this technology has already matured. For example, in the space sector, the scientific activity seems to show an acceleration in hybrid systems development in the solar field. This research field remains completely open, as evidenced by the multiplicity of technological solutions implemented. A significant part of this work has been to develop generic energy models of various modules (PV and thermal) for a multi-source generator design, based on experimental tests and existing technologies. In addition, a methodology for sizing optimisation of such generator was proposed by considering surface or volume criteria, number of thermoelectric generator (TEG) modules and temperature gradient.
\end{abstract}

Copyright () 2018 Institute of Advanced Engineering and Science. All rights reserved.

\section{Corresponding Author:}

Abdelhak lekbir

Faculty of Electrical Engineering,

Universiti Teknikal Malaysia Melaka, Hang Tuah Jaya,

76100 Durian Tunggal, Melaka, Malaysia

Email: lekbirabdelhak@gmail.com

\section{INTRODUCTION}

The global solar field finds that deserts are efficient for PV system installation due to high radiation. Nevertheless, they are characterised by their higher temperature values compared to the critical temperature of a well-functioning PV system. It is essential to understand the temperature changing effect of a PV cell on the characteristic of $I=f(V)$; the current only increases marginally with the increase in temperature. However, the temperature has a strong negative influence on the PV cell open-circuit voltage [1]. When the temperature increases, the open-circuit voltage decreases. Therefore, the maximum power of a decreasing generator will also decrease due to the rise in PV cell temperature. In industrial fields, thermal energy that appears in tools and industrial systems is considered as a loss that affects performance, therefore, the goal is to compensate for or recover the loss. Thermoelectric (TE) is a physical phenomenon characteristic of some materials contributing to green energy conversion [2], [3]. A TE material can directly convert heat into electricity by using thermoelectric generator (TEG) [4] or by moving calories via an electric current (thermoelectric cooler (TEC)) [5]. PV panels that are subject to high irradiation will lose their effectiveness because the surface, which receives radiations, can reach temperatures of up to $60-80{ }^{\circ} \mathrm{C}$ [6]. To reduce temperature, cooling systems were integrated, as reviewed by [7] and designed by [10], but the systems consumed the energy produced by the PV panels. Recent research has shown that TE modules can be integrated at the rear of solar panels to increase the amount of energy produced [5], [8], [9], [10], [11], [13]. 
Therefore, the main idea of this work is to study electrical energy generated by PV cells with and without TEG.

\section{RESEARCH METHOD}

PV energy efficiency decreases when temperature increases [14], [15]. In this work, a multi-source generator was studied; from production to consumption, in view of dimension optimally, on a point or on a given operating cycle, according to size criteria and energy produced. Therefore, a major contribution of this work consisted of the establishment of generic design templates (generators) based on the existing technologies (PV and TE). Figure 1 shows the schematic diagram of the hybrid PV/TE system.

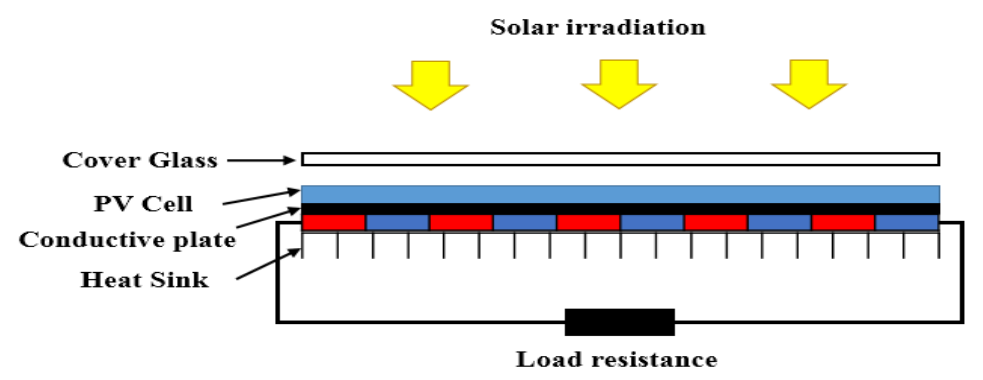

Figure 1. Schematic diagram of a hybrid photovoltaic/thermoelectric system

In high solar radiation, the surface temperature of PV panels can reach up to $80^{\circ} \mathrm{C}$, which in turn, decreases PV cells efficiency. The idea is to exploit this high temperature by placing TE modules on the back side of the PV modules so that high temperature can reach the TE modules on both sides under ambient temperature. By definition: the Seebeck effect, where current will be generated.

As can be seen in Figure 1, solar radiation reaches the PV panel after crossing the cover glass, then a conductive plate transfers heat energy from the PV panel to the TEG hot side. A heat sink removes heat from the TEG cold side. PV cell output has a relationship with irradiation and temperature. Conversely, the TEG output energy is matched directly with temperature gradient $(\Delta \mathrm{T})$, where $\Delta \mathrm{T}=\mathrm{T}_{\text {Hot }}-\mathrm{T}_{\text {cold. }}$. In this case, by assuming thermal losses between the PV cell and the conductive plate are negligible; $\mathrm{T}_{\mathrm{Hot}}=\mathrm{T}_{\mathrm{Cell}}$, also $\mathrm{T}_{\text {cold }}=\mathrm{T}_{\mathrm{amb}}$, where $\mathrm{TH}$ and TL are the TEG hot and cold side temperatures, respectively, and $\mathrm{TC}$ and $\mathrm{T}_{\mathrm{AMB}}$ are the PV cell temperature and ambient temperature, respectively. Electrical energy outputs generated by PV and TEG are matched directly together to load resistance.

\subsection{Solar Harvesting Model}

An electrical circuit with a single diode (single exponential) was considered as the equivalent PV model. Figure 2 shows the equivalent diagram of a PV cell under illumination. The PV cell corresponded to a current generator, Iph connected in parallel with a diode. Two parasitic resistances were introduced to this scheme, namely Rseries and Rshunt.

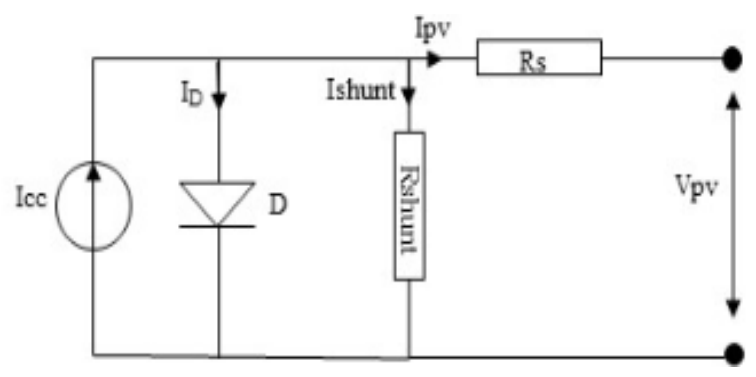

Figure 2. Equivalent diagram of a PV cell under illumination 
The mathematical model for the current-voltage characteristic of a PV cell is given by (1) [16]:

$\mathrm{I}_{\mathrm{PV}}=\mathrm{I}_{\mathrm{ph}}-\mathrm{I}_{\mathrm{sat}}\left[\exp \left(\frac{\mathrm{Vpv}+\mathrm{Ipv} \mathrm{Rs}}{\mathrm{ns} \mathrm{Vt}}\right)-1\right]$

Where, Isat is the saturation current, $\mathrm{K}$ is the Boltzmann constant $(1.381 \mathrm{x} 10-23 \mathrm{~J} / \mathrm{K})$, Ipv is the current supplied by the cell. when it operates as a generator, $\mathrm{Vpv}$ is the voltage at the terminals of the same cell; Iph is the photocurrent of the cell depending on the illumination and temperature or short-circuit current, ns is the number of PV cells in series and Vt is the junction terminal thermal voltage (V) expressed as follows:

$\mathrm{V}_{\mathrm{t}}=\frac{\mathrm{KTc}}{\mathrm{q}}$

Tc is the effective cell temperature in Kelvin $(\mathrm{K})$ and $\mathrm{q}$ is the charge of the electron $(\mathrm{q}=1,610-19 \mathrm{C})$. When Rs is very small, it can be neglected. The "Ipv Rs" from (1): the output PV cell power is expressed as:

$P_{p v}=V_{p v} I_{p v}=V_{p v} I_{p h}-V_{p v} I_{s a t}\left[\exp \left(\frac{V p v}{n s t}\right)-1\right]$

Electrical efficiency is the relation between maximum electrical power provided by Ppv cell and incident solar power. It is given by:

$\eta=\frac{\mathrm{Ppv}}{\mathrm{GA}} * 100 \%$

Where, $\mathrm{G}$ is the solar energy irradiation $\left(\mathrm{W} / \mathrm{m}^{2}\right)$ and $\mathrm{A}$ is the area of the PV panel $\left(\mathrm{m}^{2}\right)$.

\subsubsection{Thermal Harvesting Model}

Basically, thermal energy can be harvested by a solar collector. Moreover, harvesting PV cell thermal energy by using TEG can improve PV cell electrical energy performance, i.e., PV cell output efficiency. Characterisation makes it possible to study the electrical properties of a module as a function of temperatures of each face. To fully characterise a TE module, it is therefore necessary to obtain the evolution of no-load voltage and the internal resistance $(\mathrm{R})$ as a function of several parameters. The generator is able to deliver the output voltage and it is essential to design the flow path of heat to create a periodic temperature difference between the hot and cold junctions of the thermoelectric. Figure 3 shows the equivalent electric diagram.

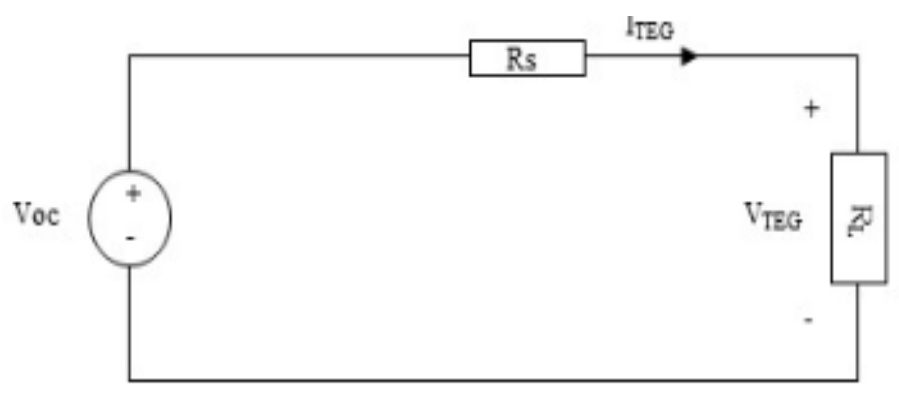

Figure 3. The equivalent diagram of a TEG

Based on the Seebeck effect, the open-circuit voltage (Voc) of a TEG enclosed in a thermal energy harvester, which composed of $\mathrm{n}$ thermocouples connected electrically in series and thermally in parallel, is expressed as follows:

$\mathrm{V}_{\mathrm{oc}}=\mathrm{S} \Delta \mathrm{T}=\mathrm{n} \alpha\left(\mathrm{T}_{\mathrm{H}}-\mathrm{T}_{\mathrm{L}}\right)$

Where, $\mathrm{S}$ and $\alpha$ are the Seebeck coefficients and $\mathrm{n}$ is the number of thermocouple. $\Delta \mathrm{T}_{\mathrm{TEG}}$ over the junctions of TEG is lower than the temperature gradient, $\Delta \mathrm{T}=\mathrm{TH}-\mathrm{TC}$. 
TEG output Courant is expressed as follows:

$I_{T E G}=\frac{n \alpha\left(T_{H}-T_{L}\right)-V_{T E G}}{R_{S, T E G}}$

The electrical power $P_{\mathrm{TEG}}\left(V_{\mathrm{TEG}}\right)$ harvested by TEG is derived as a function of its output voltage ( $\left.V_{\mathrm{TEG}}\right)$ expressed as:

$P_{T E G}\left(V_{T E G}\right)=\frac{I_{T E G} n \alpha\left(T_{H}-T_{C}\right)-V^{2} T E G}{R_{S, T E G}}$

\subsubsection{Hybrid Harvested Energy Model}

From the literature [19], the terminals output voltages of a solar panel and the thermal energy, $\mathrm{V}_{\mathrm{PV}}$ and $\mathrm{V}_{\mathrm{TEG}}$, respectively, are directly related to the load and each source is related to diodes DPV and DTEG to ensure that current flows in one direction only. An overview of the equivalent electrical hybrid energy circuit is shown in Figure 4.

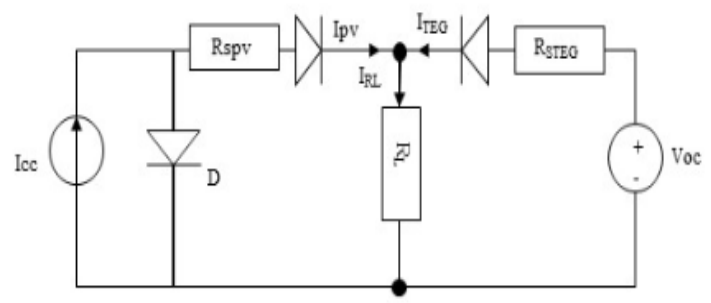

Figure 4. Hybrid system PV/TEG equivalent circuit

The maximum power generated by the hybrid system (PV/TEG) can be calculated as follows:

$P_{h y b}\left(V_{R L}\right)=\left|P_{P V}\left(V_{P V}\right)\right|+\left|P_{T E G}\left(V_{T E G}\right)\right|$

From [17], the maximum output energy can be calculated as follows:

$P_{h y b}\left(V_{R L}\right) \approx\left|V_{R L} I_{S C, P V}\right|-\left|V_{R L} I_{0}\left[\exp \left(\frac{V_{R L}}{n_{S} V_{t}}\right)\right]\right|+\left|\frac{V_{R L} V_{o c, T E G}-V^{2} R L}{R_{S, T E G}}\right|$

\section{RESULTS AND ANALYSIS}

In this session, a multi-source generator was studied in its entirety, from its production until consumption, in the optic of optimal dimensioning, on a point or on a given operating cycle and according to size criteria and energy produced.

\subsection{Simulation Of A Photovoltaic-Thermoelectric Hybrid System}

The following study will focus on the optimisation of a PV/TEG hybrid system. The objectives are as to design a digital model with MATLAB for a hybrid PV system coupled with TEG. This model will have to be validated with theoretical models or results from the literature, with an experimental bench. In addition, this work will perform system optimisation according to several parameters. The objectives to be optimised can be considered alone or in groups. The results will be analysed and commented.

\subsubsection{Simulation Of A Photovoltaic Generator}

To validate the physical model, a first analysis was done to simulate the mathematical model of the PV generator. This model was already developed in MATLAB programming language. Then, it was validated by the experimental data on the PV generator through tests performed in a laboratory. The PV generator consisted of a module containing one cell connected in series. The generator surface was $49 \mathrm{~cm}^{2}$. The normal operating temperature $(\mathrm{Tc})$ was $27{ }^{\circ} \mathrm{C}$. The simulation result with series and parallel resistors 
values, Rs $=0.000051435 \Omega$ and $\mathrm{Rsh}=5 \times 10^{5} \Omega$, respectively, and solar irradiation of $950 \mathrm{~W} / \mathrm{m}^{2}$ are shown in Figure 5.

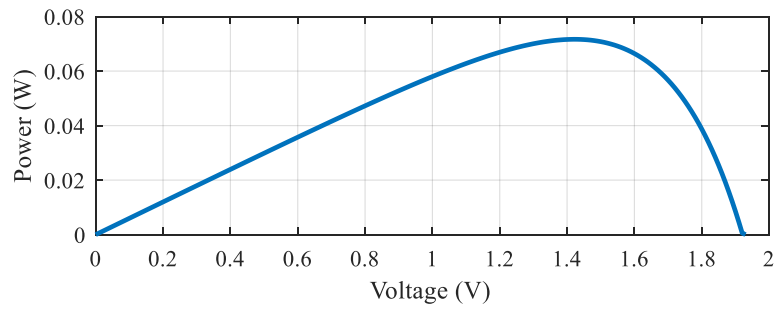

Figure 5. The Characteristic $P_{P V}=f\left(V_{P V}\right)$

PV arrays are inherently nonlinear sources that require a good estimate on the optimum point of operation for real-time control. This power varies according to climatic factors such as temperature and irradiation. The curve characteristic will introduce different rates depending on temperature. The open-circuit voltage will decrease when the temperature increases, in contrast to the short-circuit current. The change in no-load voltage is almost compensated for by the variation of the short-circuit current.

\subsubsection{Simulation Of A Thermoelectric Generator}

To evaluate the analytical model of a TE module, MATLAB simulation of the equivalent electrical model was performed with a load resistance connected at the output of the TE generator. The simulation was carried out for a module composed of 127 thermocouples containing the Seeback coefficient, $\alpha=0.00049$ $\mathrm{mV} / \mathrm{k}$ with internal resistance of $5.8 \Omega$ and temperature gradient of $13.18{ }^{\circ} \mathrm{C}$. According to Figure 6 , to improve module efficiency so that the system overall efficiency was higher, voltage $(\mathrm{V})$ was increased (half of the open-circuit voltage corresponding to the TE maximum power).

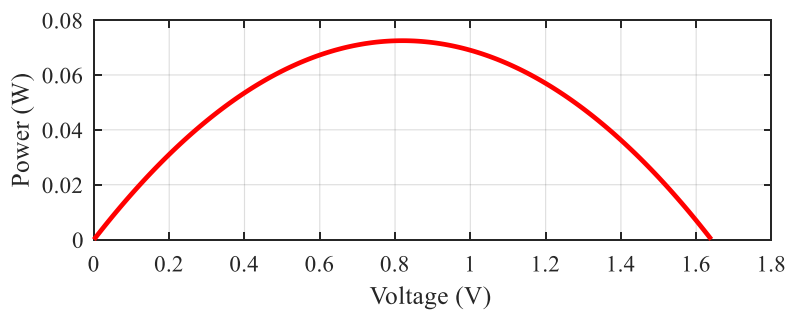

Figure 6. Characteristic of $\mathrm{P}_{\mathrm{TEG}}=\mathrm{f}\left(\mathrm{V}_{\mathrm{TEG}}\right)$

\subsubsection{Simulation Of A Pv/Teg Hybrid System}

To illustrate the thermal and PV energy coupling of a hybrid system recovering the heat of the panel and electrically connected to a PV cell, Figure 7 shows the power curves of PV module, TEG module and the hybrid system. Depending on the voltage, maximisation of the hybrid system output power can be noticed. The curves were plotted with the previously defined parameters.

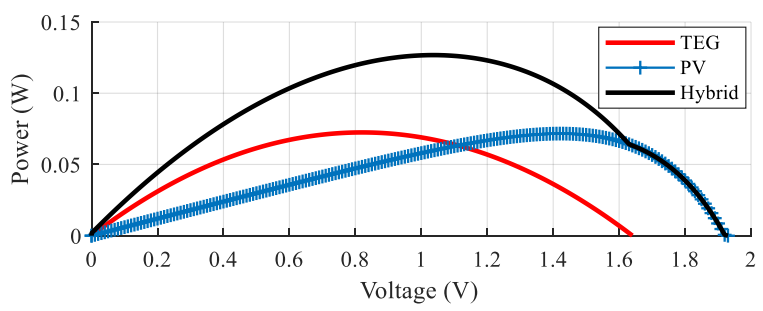

Figure 7. Power characteristics of hybridisation as a function of VRL 
Figure 7 shows the hybrid energy from both PV and TEG, and a summation curve. The open-circuit voltage of the TEG was smaller than the PV cell because of the temperature gradient applied to the TEG. Accordingly, hybrid energy is the sum of two generated energies from PV and TEG and the overall electrical energy is similar to the PV energy after the interval of the TEG voltage.

\subsection{Practical Validation With Comparison Results}

This section presents the configuration for both structures and the two experiments performed to maximise energy of PV cell from the hybrid system. The experimental tests were prepared and carried out in a laboratory. The measurements taken by the two configurations are presented as follows:

\subsubsection{PV Cell}

The experimental results made it possible to validate the analytical model of power as a function of voltage. The results are shown in Figure 8.

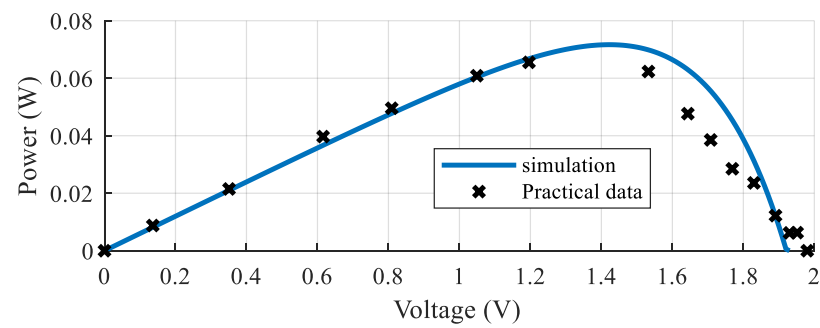

Figure 8. Simulation and experimental characteristic of $P_{\mathrm{TEG}}=\mathrm{f}\left(\mathrm{V}_{\mathrm{TEG}}\right)$

It should be noted that the increase in the short-circuit current was much greater than the increase in the open-circuit voltage, since the short-circuit current (Isr) was a linear function of the illumination and the open-circuit voltage (Voc) was a logarithmic function. Moreover, the power delivered by the PV generator depended much more on the variation of illumination than the variation of temperature.

The experimental study allowed calculation of maximum power of PV module and optimal point of model operation either under the influence of temperature, illumination or both. Comparison between the practical measurements and those of the power-voltage simulation curves of the PV cell showed a good correlation between the theoretical model and the practical data, except when the voltage was beyond $1.2 \mathrm{~V}$, a small discrepancy between the practical values and the simulation can be noticed. This was mainly due to weather conditions and imperfect measurements.

\subsubsection{TEG Module}

In this part, the experimental results made it possible to validate the analytical model of the electrical power generated as a function of the voltage as shown in Figure 8.

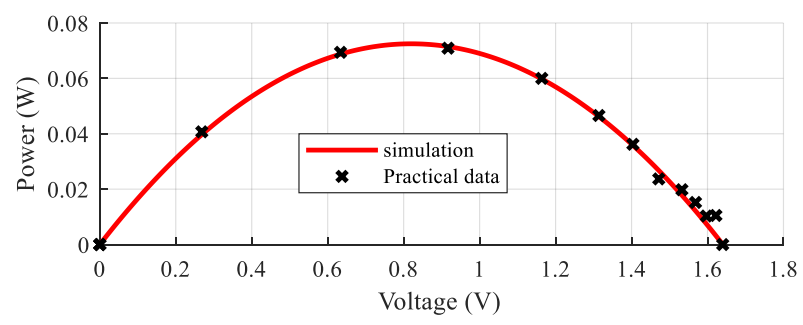

Figure 9: The simulation and experimental characteristic of $\mathrm{P}_{\mathrm{TEG}}=\mathrm{f}\left(\mathrm{V}_{\mathrm{TEG}}\right)$

Based on Figure 9, it can be seen that the power generated depended closely on the TE gradient and the Seebeck coefficient. The connection mode of the TEG system can be optimised to generate the desired energy level. It was clear that, in order to maximise the electrical energy produced by the generator, it must realise the system in two structures; planar and vertical, which is half of the open-circuit voltage. The 
comparison between the practical measurements and those of the power-voltage simulation curves of a TEG shows a good correlation between the theoretical model and the practice model.

\subsubsection{Hybrid Energy System}

In this part, the testing of the proposed hybrid prototype was done using two generators in parallel. Figure 10 shows the simulation and experimental characteristic of the power as a function of voltage generated by the PV/TEG hybrid system

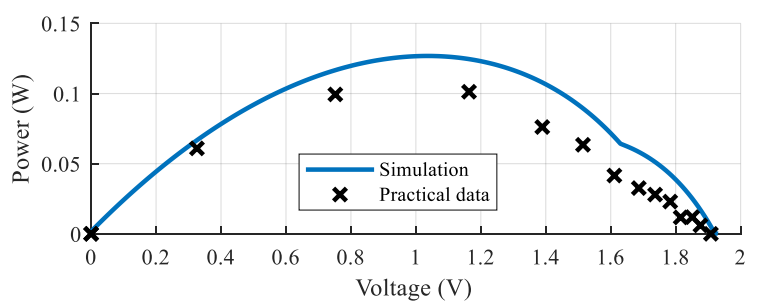

Figure 10. The simulation and experimental characteristic of $P_{\text {hyb }}=f\left(V_{\text {hyb }}\right)$

There is a good correlation between the theoretical model and the practice model. The first advantage of the proposed configuration is the increase in power generated compared to the conventional technique due to the exploitation of the thermal effect. Secondly, the generated power increases with a decrease of the PV cell surface and consequently the increase of energy density.

The objective of this research is to validate the utilisation of the exploited thermal effect to increase PV cell efficiency. The simulation results and experimental measurements carried out in this part made it possible to validate the analytical model proposed by the practical measures carried out in the laboratory. Finally, the proposed model was validated.

\section{CONCLUSION}

In this paper, a mathematical model was established for energy maximisation. By using a hybrid prototype (for simplicity), the power generated was multiplied by a factor of more than $75 \%$. This effect made possible a significant increase in the converted power. The experimental results that confronted the theory were satisfactory for energy recovery. Finally, through a specific test bench for energy management, a complete generation system was assessed.

\section{ACKNOWLEDGEMENTS}

The authors would like to gratefully acknowledge the research funding provided by the Universiti Teknikal Malaysia Melaka under the research grant S01482 PJP/2016/FKE/HI5 and UTeM scholarship (Zamalah Scheme) for PhD financial support.

\section{REFERENCES}

[1] M. Louzazni, E. H. Aroudam, and H. Yatimi, "Modeling and Simulation of A Solar Power Source for a Clean Energy without Pollution," vol. 3, no. 4, pp. 568-576, 2013.

[2] I. Lashkevych, C. Cortes, and Y. G. Gurevich, "Physics of thermoelectric cooling: Alternative approach," J. Appl. Phys., vol. 105, no. 5, 2009.

[3] Y. Pan, B. Lin, and J. Chen, "Performance analysis and parametric optimal design of an irreversible multi-couple thermoelectric refrigerator under various operating conditions," Appl. Energy, vol. 84, no. 9, pp. 882-892, 2007.

[4] W. H. Chen, C. Y. Liao, and C. I. Hung, "A numerical study on the performance of miniature thermoelectric cooler affected by Thomson effect,” Appl. Energy, vol. 89, no. 1, pp. 464-473, 2012.

[5] P.A. Nair.\&. P Balakrishnan, B. Benziger, "Review Paper on Thermoelectric Air-Conditioner Using Peltier Modules," Int. J. Mech. Eng., vol. 4, no. 3, pp. 49-56, 2015.

[6] G. Rockendorf, R. Sillmann, L. Podlowski, and B. Litzenburger, "PV-hybrid and thermoelectric collectors," Sol. Energy, vol. 67, no. 4-6, pp. 227-237, 1999.

[7] A. Royne, C. J. Dey, and D. R. Mills, "Cooling of photovoltaic cells under concentrated illumination: A critical review," Sol. Energy Mater. Sol. Cells, vol. 86, no. 4, pp. 451-483, 2005.

[8] A. R. Amelia et al., "Cooling on photovoltaic panel using forced air convection induced by DC fan," Int. J. Electr. Comput. Eng., vol. 6, no. 2, pp. 526-534, 2016.

[9] W. G. J. H. M. van Sark, "Feasibility of photovoltaic - Thermoelectric hybrid modules," Appl. Energy, vol. 88, no. 8, pp. 2785-2790, 2011. 
[10] T. Liao, B. Lin, and Z. Yang, "Performance characteristics of a low concentrated photovoltaic-thermoelectric hybrid power generation device," Int. J. Therm. Sci., vol. 77, pp. 158-164, 2014.

[11] R. Kiflemariam, M. Almas, and C. Lin, "Modeling Integrated Thermoelectric Generator-Photovoltaic Thermal (TEG-PVT ) System," Proc. 2014 COMSOL Conf., pp. 1-5, 2014.

[12] Y. Y. Wu, S. Y. Wu, and L. Xiao, "Performance analysis of photovoltaic-thermoelectric hybrid system with and without glass cover," Energy Convers. Manag., vol. 93, pp. 151-159, 2015.

[13] R. Bjørk and K. K. Nielsen, "The performance of a combined solar photovoltaic (PV) and thermoelectric generator (TEG) system,” Sol. Energy, vol. 120, pp. 187-194, 2015.

[14] G. Li, G. Pei, J. Ji, and Y. Su, "Outdoor overall performance of a novel air-gap-lens-walled compound parabolic concentrator (ALCPC) incorporated with photovoltaic/thermal system,” Appl. Energy, vol. 144, pp. 214-223, 2015.

[15] G. Li, G. Pei, J. Ji, M. Yang, Y. Su, and N. Xu, "Numerical and experimental study on a PV/T system with static miniature solar concentrator," Sol. Energy, vol. 120, pp. 565-574, 2015.

[16] A. N. Celik and N. Acikgoz, "Modelling and experimental verification of the operating current of mono-crystalline photovoltaic modules using four- and five-parameter models," Appl. Energy, vol. 84, no. 1, pp. 1-15, 2007.

[17] Y. K. Tan, S. Member, S. K. Panda, and S. Member, "Energy Harvesting from Hybrid Indoor Ambient Light and Thermal Energy Sources for Enhanced Performance of Wireless Sensor Nodes," IEEE Trans. Ind. Electron., vol. 58, no. 9 , pp. 4424-4435, 2011.

\section{BIOGRAPHIES OF AUTHORS}
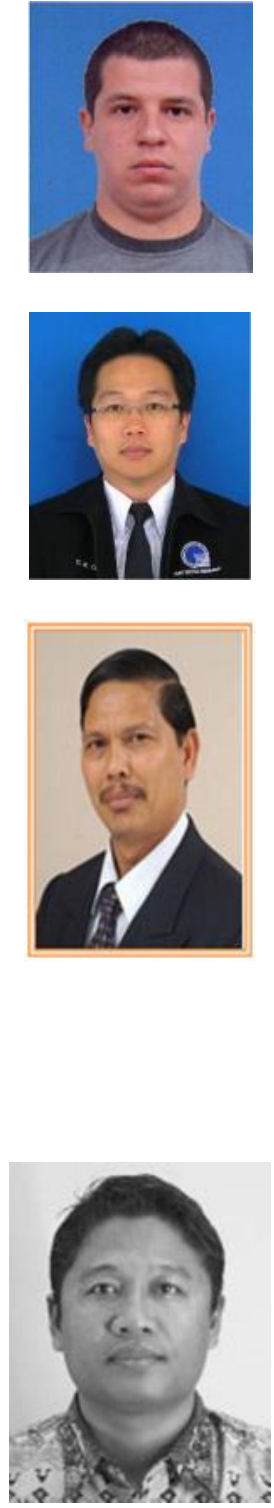

Abdelhak lekbir received his B.Eng in electrical engineering in 2013 and his M.Eng in control of electrical systems in 2015 from Mehammed EL Bachir El Ibrahimi University Bordj Bou Arreridj Algeria. He is currently a PhD student at Universiti Teknikal Malaysia Melaka (UTeM).

Chin Kim Gan received his B.Eng and M.Sc degrees both in electrical engineering from the Universiti Teknologi Malaysia (UTM) and PhD degree from the Imperial College London, UK. He is currently an Associate Professor at the Universiti Teknikal Malaysia Melaka (UTeM). His research interests are distribution network design, integration of renewable energy and smart grid.

Mohd Ruddin Ab. Ghani is a professor and was the Rector of the Universiti Teknikal Malaysia Melaka (UTeM). Before coming to UTeM, He was professor and the dean of the Faculty of Electrical Engineering at Universiti Teknologi Malaysia (UTM). Prof. Mohd. Ruddin Ab. Ghani obtained his Ph.D. in Systems Engineering and Control from the University of Manchester Institute of Science and Technology in 1989. His current research interests include: dynamic economic load dispatch, unit commitment, distribution automation, optimization of large scale power systems, system identification, expert system applications and advanced control techniques to power systems. He has published over 90 papers and articles in the related fields. Besides actively involved in research and publications, he is also a committee member of various distinguished boards such as: committee member of Malaysian International Electro-technical Commission (IEC), Intensification of Research in Priority Areas (IRPA) and IEEE Malaysia chapter. He is also member of Advisory Council Member of Malaysian Armed Forces Academy, IEEE Control System Society (1989) and a member of Energy Technology under Economic planning unit.

Tole Sutikno (M'07) received the B.Eng. degree in electrical engineering from Diponegoro University (UNDIP), Semarang, Indonesia, in 1999, and the M.Eng. Degree in power electronics from Gadjah Mada University (UGM), Yogyakarta, Indonesia, in 2004. He is currently working toward the Ph.D. degree in the Department of Energy Conversion, Faculty of Electrical Engineering, Universiti Teknologi Malaysia, Johor, Skudai, Malaysia. Since 2001, he has been a Lecturer in the Electrical Engineering Department, Universitas Ahmad Dahlan, Yogyakarta. His research interests include the fields of power electronics, motor drive systems, and field programmable gate array applications. 